\title{
A AUTOCOMPOSIÇÃO COMO FORMA DE CONCRETIZAÇÃO DA EFICIÊNCIA ADMINISTRATIVA
}

\author{
The autocomposition as a form of concretization of administrative \\ efficiency
}

\section{Felipe Barbosa de Menezes}

Mestre em Direito Processual pela Universidade Federal do Espírito Santo (UFES). Pós Graduado em Direito Público com Ênfase em Magistério Superior pela UNISUL/SC. Graduado em Direito pela Faculdade de Direito de Vitória (FDV). Membro da Comissão de Advogados Públicos da OAB-ES (desde 2012). Procurador do Município de Cariacica-ES. Advogado e Consultor Jurídico. Endereço para correspondência: Rua Professor Almeida Cousin, 125, Sala 1709, Ed. Enseada Trade Center, Enseada do Suá - Vitória/ES. Telefone: (27) 3039-8006. Email: fbmenezes.adv@gmail.com.

\section{Aurélio Ferreira de Moraes Neto}

Graduando em Direito pela Universidade Federal do Espírito Santo (UFES). Estagiário no escritório Alves Hibner Advogados Associados. Endereço para correspondência: Avenida Saturnino Rangel Mauro, 1231, Ap. 101, Pontal de Camburi- Vitória/ES - CEP: 29062033. Telefone: (27) 99779-6087. Email: aaurelioferreira@gmail.com.

\section{Resumo}

O presente trabalho traça uma análise da evolução dos meios adequados de resolução de conflitos, especialmente no que tange a sua aplicação em litígios envolvendo a Administração Pública. Para tanto, se analisará a Resolução 125/2010 do CNJ, bem como a Lei 13.140/2015, que regula a prática da mediação. Por fim, sob análise do princípio do interesse público e sua compatibilidade com os meios consensuais, se buscará compreender a utilização destes como forma de concretização do princípio da eficiência administrativa.

Palavras-chaves: Autocomposição. Administração. Eficiência. linteresse. Princípio

\section{Abstract}

This paper presents an analysis of the evolution of adequate means of conflict resolution, especially regarding its application in disputes involving Public Administration. To this end, CNJ Resolution 125/2010 will be analyzed, as well as Law 13.140 / 2015 , which regulates the practice of mediation. Finally, under analysis of the principle of public interest and its compatibility with consensual means, an attempt will be made to understand the use of these as a form of implementation of the principle of administrative efficiency.

Keywords: Self-composition. Administration. Efficiency. Interest. Principle

\section{Sumário}

1. Introdução; 2. A Crise no Judiciário Brasileiro e as falhas na utilização exclusiva dos meios heterocompositivos; 3 . O CPC de 2015 e o incentivo aos métodos autocompositivos; 4. A aplicação dos métodos consensuais de resolução de conflitos em litígios envolvendo a Administração Pública; 5. A utilização da autocomposição como forma de concretização do princípio da eficiência administrativa; 6. Conclusão; 7. Notas; Referências 


\section{INTRODUÇÃO}

A Administração Pública e todos os seus componentes possuem um regime jurídico próprio, repleto de peculiaridades e prerrogativas. Além disso, o rol de princípios que moldam sua atuação é extenso, havendo, muitas vezes, dificuldades em aplicá-los. Princípios como a legalidade, a eficiência, o interesse público e o dever de autotutela, vez ou outra, necessitam ser compatibilizados para a uma atuação adequada da máquina pública.

É nesse cenário (de compatibilização de princípios) que se situam os métodos alternativos de conflitos, especialmente aqueles caracterizados pela consensualidade. Afinal, é possível aplicá-los sem infringir princípios como a legalidade e o interesse público? Outrossim, sua aplicação pode funcionar como uma forma de concretização de outros princípios, como o da eficiência administrativa? É no cerne dessas questões que o presente trabalho irá se concentrar.

Como veremos, os métodos consensuais de resolução de conflitos, caracterizados por serem uma segunda via para a resposta de um litígio, diferente da Jurisdição Estatal, poderão ser utilizados pela Administração Pública, para que esta possa resolver os seus litígios de uma forma mais adequada, célere e eficiente.

Assim, desde que seja respeitado determinados critérios, não há de se falar em impossibilidade da Administração de utilizar os métodos consensuais de resolução. Uma vez que estes, se utilizados da forma adequada, poderão ser meios para alcance de fins últimos dos órgãos estatais, como o interesse público e a própria eficiência no agir administrativo.

\section{A CRISE NO JUDICIÁRIO BRASILEIRO E AS FALHAS NA UTILIZAÇÃO EXCLUSIVA DOS MEIOS HETEROCOMPOSITIVOS}

A complexidade do meio social, repleto de pessoas distintas, com formações culturais heterogêneas, faz com que surjam diversos conflitos entre os seus componentes. A princípio, o Direito Estatal surgiu como o meio mais eficiente para a solução de tais litígios, especialmente na figura do Estado-Juiz. Utilizando-se de um viés histórico, pode-se dizer que a justiça primitiva (MIRANDA, 1997, p.170), pautada na resolução de conflitos pela utilização da força, isto é, a autotutela, foi sendo substituída pelo monopólio da justiça estatal, através do exercício da Jurisdição. Tal forma de dirimir conflitos possui como características principais, a heterocomposição e a imparcialidade (DIDIER JR., 2007, p. 156/157). Isso significa dizer que, na hipótese de surgimento de um conflito, este será solucionado através de um terceiro imparcial, o Estado, que será responsável por aplicar a decisão ao caso concreto. Essa lógica de espera por uma decisão, por parte das partes, perdurou por muitos anos na cultura processual, especialmente na brasileira.

Tal modelo resolutivo, pautado na espera por uma solução pronta, feita por um terceiro imparcial (Estado), foi, por muitos anos, adotado de forma exclusiva no sistema processual brasileiro. Com o passar do tempo, percebeu-se suas falhas, passando a se discutir novas formas de solução de litígios, os chamados meios alternativos de resolução de conflitos (EIDT, 2015, p.60).

Em primeiro lugar, há de se dizer que o próprio modelo de Estado Brasileiro atual, 
pautado num sistema democrático e participativo, não se adequa à noção de Estado como única forma de solução de litígios. A ideia de uma relação processual, envolvendo as parte e o juiz, onde se espera, exclusivamente, um provimento final do órgão estatal, passa a se tornar defasada. A compreensão de que o Juiz é o único capaz de solucionar os litígios apresentados, pautada em brocardos latinos como iura novit curiae e da mihi factum, dabo tibi ius (ALVARO DE OLIVEIRA, 1998, p. 64), já não se adequa à noção de Estado Democrático participativo. Em tal modelo, onde a participação popular é tão importante, não se pode pensar num processo onde as partes se encontram inertes, aguardando a resposta de um terceiro estranho ao problema. Exige-se uma maior participação dos envolvidos no litígio, para que eles, de forma autônoma, possam construir a solução adequada para o problema (CAMBI; MACHADO DE SOUZA, 2017, p. 131). Isso é o que chamamos de autocomposição, elemento indissociável da maioria dos métodos alternativos de resolução de conflitos. Seguindo essa linha de raciocínio, Eduardo Cambi e Fernando Machado de Souza (2017, p. 131) lecionam:

É preciso superar a cultura da sentença como único modo de solução do conflito, pois tal forma de composição dos litígios é insatisfatória, pois mesmo quem obtém a tutela jurisdicional, precisa arcar com a duração, nem sempre célere, do processo judicial. Logo, devem ser incentivados os métodos alternativos de solução de controvérsias, reservando a tutela tradicional somente àqueles casos em que a utilização de tais meios se mostrem inviáveis.

Adentrando ainda nos problemas dessa cultura heterocompositiva de litígios, faz-se necessário destacar as dificuldades do próprio Estado na prestação jurisdicional. O excesso de litígios - principalmente após a onda de acesso à Justiça, surgida no final do século XX (CAPPELLETTI, 1988) -, somados à ineficácia do judiciário, faz com que a prestação jurisdicional se torne cada vez mais morosa, diminuindo gradativamente a confiança do cidadão nas instituições do judiciário brasileiro. De acordo com Elisa Berton Eidt (2015, p.59) e conforme dados do ICJ Brasil (Índice de Confiança no Judiciário), relacionados ao $2^{\text {ao }} \mathrm{e}$ ao $3^{\circ}$ trimestre de 2014, constata-se que "a má avaliação do judiciário como prestador de serviços públicos segue a tendência, já identificada nos períodos anteriores. Para $89 \%$ dos entrevistados o Judiciário é moroso, resolvendo os conflitos de forma muito lenta ou muito lentamente."

Ainda nesse sentido, o "Relatório Justiça em Números 2015" (CNJ, 2015) revela que tramitaram no Brasil 99,7 milhões de processos no ano de 2014, sendo que 91,9 milhões encontravam-se no primeiro grau, o que corresponde a $92 \%$ do total. Além disso, informa que a capacidade produtiva anual da Justiça de Primeiro Grau é de apenas $27 \%$ da demanda (casos novos + acervo) imposta à sua apreciação. Isto significa que o Judiciário Brasileiro precisaria ficar praticamente quatro anos parado, sem nenhum processo novo, para que se pudesse concluir todos os litígios pendentes.

Como se vê, tais dados são alarmantes, fazendo-se necessária a busca por outras formas de solução de litígios, distintas da jurisdição estatal. O monopólio de Jurisdição pelo Estado não torna o poder judiciário o único meio para dirimir litígios (PINHO, 2011, p.53). Como se verá, existe uma segunda via, a dos chamados métodos alternativos de resolução (arbitragem, conciliação e mediação). Assim, a junção de todos esses meios de solução (heterocompositivos e autocompositivos) configurará um verdadeiro sistema multiportas de 
prestação de Justiça (CUNHA, 2017, p. 640), onde o cidadão optará pelo instrumento de solução mais adequado ao seu litígio.

Destarte, há de se ressaltar que o próprio Estado, enquanto parte no processo, deve se adequar ao novo modelo de resolução de litígios. Até porque, na atual conjuntura do Judiciário Brasileiro, a Administração Pública é a pessoa que mais figura como parte nos processos. Assim, após adentrar nos tipos alternativos de resolução de conflitos, se vislumbrará a aplicação de tais meios como forma de concretização de um Estado eficiente, seja ele como parte ou como prestador de Justiça.

\section{O CPC DE 2015 E O INCENTIVO AOS MÉTODOS AUTOCOMPOSITIVOS}

O novo CPC alterou toda a dinâmica do sistema processual brasileiro, trazendo diversas novidades. Pautado em premissas distintas do modelo anterior (CPC/73), tais como a celeridade, a informalidade e a valorização do julgamento do mérito, o novo modelo veio como forma de dar maior efetividade aos processos brasileiros.

Nesse sentido, em que pese a utilização das premissas citadas anteriormente, o novo código também traz uma outra, tão importante quanto as demais: a valorização dos chamados "meios alternativos de resolução de conflitos", isto é, a mediação, a conciliação e a arbitragem. Esses métodos alternativos foram introduzidos no novo código, sendo extremamente valorizados como forma de solução de controvérsias das quais a sociedade tem a seu dispor (EIDT, 2015, p.60). Assim, ressalta-se, desde já, que tais meios de resolução não são alternativas ao mau funcionamento do Judiciário, mas sim, alternativas possíveis para a resolução de cada tipo de controvérsia.

Dessa forma, conforme entendimento de Leonardo Carneiro da Cunha (2017, p. 639), o termo mais adequado a ser utilizado seria "meios adequados de resolução de conflitos", uma vez que cada forma de solução seria adequada para resolver um tipo de litígio, formando um verdadeiro "Sistema de Justiça MultiportaS" (CUNHA, 2017, p. 640), e abandonando a ideia de Jurisdição estatal como forma exclusiva de solução de litígios em uma sociedade.

Passada essa análise preliminar, nas próximas linhas será discutida a importância que o novo CPC deu para os métodos alternativos de conflitos, especialmente os consensuais, nas figuras da conciliação e da mediação. A arbitragem, por também se tratar de um meio heterocompositivo, assim como a jurisdição estatal, não será tratada no presente trabalho, sendo importante destacar apenas aqueles meios que se distanciam do modelo heterocompositivo de resolução, como bem demonstrado anteriormente.

O CPC/2015 buscou incentivar a adoção dos meios autocompositivos de resolução de conflitos (mediação e conciliação), conforme se observa na parte responsável por disciplinar suas normas fundamentais. Logo em seu art. $3^{\circ}, \S \S 2^{\circ}$ e $3^{\circ}$, fica determinado que o Estado deverá promover a solução consensual dos conflitos, bem como estipula que todas as partes envolvidas no processo devem incentivar a adoção da conciliação, da mediação e de outros meios consensuais. Segundo Leonardo Carneiro da Cunha (2017, p. 654): 
de conflitos. Isso propicia um redimensionamento e democratização do próprio papel do Poder do Judiciário e do modelo de prestação jurisdicional pretendido.

Além do incentivo, o código, em seus arts. 165 a 175, também disciplina e conceitua tais institutos, traçando os seus parâmetros de aplicabilidade.

No que se refere à conciliação, esta pode ser definida como um meio autocompositivo de resolução de conflitos, onde não há um vínculo anterior entre as partes, com possibilidade de atuação ativa do conciliador na propositura de soluções alternativas, sem qualquer tipo de constrangimento ou intimidação para que as partes conciliem (CAMBI; MACHADO DE SOUZA, 2017, p. 135/136).

Apesar do novo código ter atribuído tamanha importância para tal instituto, estabelecendo sua obrigatoriedade de ocorrência antes mesmo do réu apresentar contestação (Art. 334, CPC/2015), já se discutia sua aplicação em meados do ano de 2010 , quando foi implementada a resolução 125/2010 do CNJ, que trazia os parâmetros gerais de aplicação da conciliação e da mediação.

Já em relação à mediação, é possível defini-la como um outro meio autocompositivo de resolução de conflitos, onde as partes possuem um vínculo anterior ao litígio, e que o mediador é responsável por reestabelecer o diálogo entre os envolvidos, para que estes, sozinhos, possam negociar uma solução. Assim, diferentemente da conciliação, o papel do mediador não é tão ativo, sendo restrito ao restabelecimento do diálogo entre as partes (CAMBI; MACHADO DE SOUZA, 2017, p. 136).

Destaca-se que, apesar das diferenças, tais meios autocompositivos possuem a mesma lógica de aplicação, isto é, a possibilidade das partes, de forma autônoma, chegarem a um consenso e resolverem o litígio elas mesmas. Ademais, o próprio código, em seu art. 166, traça os princípios norteadores de ambos os meios, sendo eles: a) independência; b) imparcialidade; c) autonomia da vontade; d) confidencialidade; e) oralidade; f) informalidade; e g) decisão informada.

Por fim, faz-se necessário dizer que, com a valorização desses meios consensuais no nosso sistema processual, começaram a surgir diversas discussões sobre a sua aplicabilidade em litígios envolvendo a Administração Pública como parte, principalmente em virtude do princípio da indisponibilidade do interesse público. Diante de tais discussões, criou-se a Lei 13.140/2015, responsável por regulamentar a mediação e a sua aplicação em tais tipos de litígios.

\section{A APLICAÇÃO DOS MÉTODOS CONSENSUAIS DE RESOLUÇÃO DE CONFLITOS EM LITÍGIOS ENVOLVENDO A ADMINISTRAÇÃO PÚBLICA}

A observância de alguns critérios para a utilização da autocomposição na resolução de um litígio, é imprescindível para a correta aplicação dessa técnica. São, basicamente, três requisitos indispensáveis para uma correta aplicação dos meios consensuais: a observância da ordem pública e do bom costume; o consenso entre as partes; e a disponibilidade do direito sacrificado (PERLINGUEIRO, 2017, p. 127 apud PICARDI, 2010). 
No que tange ao primeiro, não há muitas discussões, pois a homologação de acordo judicial ou extrajudicial dependerá da observância das normas fundamentais e regramentos da ordem jurídica vigente. Já em relação ao consenso, podemos afirmar que este faz parte da própria essência dos métodos autocompositivos, uma vez que as partes, para chegarem em uma solução de forma autônoma, precisam concordar entre si.

O problema que surge - principalmente em relação à possibilidade de aplicação dos meios autocompositivos no âmbito da Administração Pública - é em relação ao último requisito: a disponibilidade do direito sacrificado no litígio. Como se sabe, a Administração Pública é regida por diversos princípios e regras, distintos, muitas vezes, da legislação aplicada nas relações privadas. Uma dessas regras norteadores da atuação administrativa é o interesse público. Tal disposição "deve ser sempre o norte da atividade administrativa" (PERLINGUEIRO, 2017, p. 132). Assim, todo o agir administrativo - seja ele no âmbito extrajudicial ou na esfera judicial, isto é, na forma de Administração Pública ou na de Fazenda Pública (CUNHA, 2017 , p. 15) - deve ser pautado no respeito aos interesses da sociedade como um todo.

Partindo-se disso, pode-se definir tal conceito como sendo o conjunto de interesses de todos os indivíduos, porém, concentrado na figura de um único ente, a sociedade. Esse interesse deve ser preservado e defendido em toda atuação da Administração Pública, sendo vedada a sua disponibilidade pelo Estado. Afinal, aparentemente, resta impossível dispor aquilo que não Ihe pertence. Nesse mesmo sentido, segundo Elisa Berton Eidt (2015, p. 67):

\footnotetext{
O interesse público é regulado pelo regime do direito público, que possui como fundamentos a sua supremacia e a sua indisponibilidade, além da sua adstrita observância ao princípio da legalidade.
}

Deste modo, diante da obrigatoriedade de respeito ao interesse público, imposta à máquina administrativa, bem como da proibição de sua disponibilidade, como aplicar os métodos autocompositivos no âmbito dos litígios envolvendo a Administração pública/Fazendo Pública? Como veremos, a resposta não é tão simples.

Em primeiro lugar, valendo-se da classificação de Renato Alessi, ora adotada por Celso Antônio Bandeira de Mello (2006, p. 62/63), faz-se necessário a distinção do interesse público em primário e secundário, para que, só assim, se possa analisar as possibilidades de aplicação dos meios autocompositivos.

O interesse primário seria aquele relacionado aos interesses de toda coletividade, cujo alcance é atingido pelas funções precípuas do Estado, sendo vetada a sua disponibilidade. Já o secundário, seria o interesse relacionado ao Estado enquanto pessoa jurídica, dotada de direito e obrigações e com interesses próprios de natureza patrimonial. Segundo Bandeira de Melo (2006, p. 62/63), tal interesse seria disponível. Vejamos:

\footnotetext{
[...] Assim, independentemente do fato de ser, por definição, encarregados dos interesses públicos, o Estado pode ter, tanto quanto as demais pessoas, interesses que lhe são particulares, individuais, e que, tal como os interesses delas, concebidas em suas meras individualidades, se encarnam no Estado enquanto pessoa.
}

Assim, sendo disponíveis os direitos relacionados a esse tipo de interesse, logo, também serão passíveis de serem dispostos em eventuais litígios envolvendo a Administração Pública, utilizando da autocomposição para tanto. 
Via de regra, as relações que envolvem o interesse público secundário, e por consequência, direitos que a Administração Pública pode dispor, são de esfera patrimonial. Nesses tipos de relações, a Administração Pública "se encontra no mesmo nível do particular, agindo sem qualquer manifestação de autoridade" (CAMBI; MACHADO DE SOUZA, 2017, p. 134). Em tais condições, respeitando o próprio princípio da igualdade, que também rege a atuação da Administração Pública, não se faz razoável limitar a atuação da autoridade administrativa, no que diz respeito à possibilidade de dispor interesses. Seria um contrassenso à própria lógica das relações privadas, caracterizada pelo autorregramento das partes envolvidas (CAMBI; MACHADO DE SOUZA, 2017, p. 135).

Ressalta-se, entretanto, que a atuação da Administração Pública em uma relação de direito privado não se dá da maneira irrestrita. "Ela deve sempre respeitar os direitos fundamentais, bem como os demais princípios inerentes à atividade administrativa" (CAMBI; MACHADO DE SOUZA, 2017, p. 136). Dessa forma, apesar da possibilidade de dispor direitos, não se pode ultrapassar os limites impostos constitucionalmente à Administração Pública. Assim, segundo Heitor Sica (2015, p. 2 e 3):

\begin{abstract}
Parece razoável o entendimento de que os direitos patrimoniais da Fazenda Pública são disponíveis nos limites traçados pelo ordenamento jurídico, baseado na mais simples ideia de princípio da legalidade. Ou seja, é necessária norma jurídica expressa para definir quais direitos da Fazenda os agentes públicos que a representam podem dispor, e os limites e condições para que assim o façam, sem que com isso se considere ferida a indisponibilidade do interesse público.
\end{abstract}

É justamente por isso que, pautando-se nessa linha de raciocínio, foi promulgada a Lei 13.140/2015, responsável por regulamentar a prática da mediação de um modo geral, bem como sua utilização nos litígios envolvendo pessoas jurídicas de direito público. Para alguns autores, essa legislação passou a ter tamanha importância, que pode ser considerada como sendo o novo marco da mediação no Brasil (FAGUNDEZ; GOULART, 2016, p.151), ampliando, ainda mais, o reconhecimento dado aos meios autocompositivos pela Resolução 125/2010 do CNJ.

Logo de imediato, em seu art. $3^{\circ}$, percebe-se a incidência da discussão travada anteriormente, no que diz respeito à possibilidade de autocomposição em litígios envolvendo direitos disponíveis e indisponíveis. O legislador esclarece que só poderá "ser objeto de mediação o conflito que verse sobre direitos disponíveis ou sobre direitos indisponíveis que admitam transação" (Art. $3^{\circ}$, Lei 13.140/15). Assim, a princípio, a Administração Pública só poderá realizar transações envolvendo direitos disponíveis (relacionados ao interesse público secundário), além dos direitos indisponíveis que admitam transação.

Segundo tal diploma, a mediação será implementada, no âmbito dos litígios envolvendo pessoas jurídicas de direito público, por meio da criação de câmaras de prevenção e resolução administrativa de conflitos (Art. 32, Lei 13.140/15). Essas terão o seu funcionamento e composição dispostos em regulamento próprio (Art. 32, $\S 1^{\circ}$, Lei 13.140/15), sendo vinculadas ao seu respectivo órgão federado. Ademais, os casos que poderão ser suscetíveis à transação também estarão determinados em regulamento (Art. 32, § $2^{\circ}$, Lei 13.140/15).

No que tange aos órgãos vinculados à Administração Pública direta, suas autarquias e fundações, o procedimento é um pouco distinto, sendo mais rígido. A solução consensual 
se dará através da chamada transação por adesão, cujo o fundamento deve se encontrar respaldada por autorização do Advogado-Geral da União, com base em jurisprudência pacífica dos STF ou de tribunais superiores; ou parecer do Advogado Geral da União, aprovado pelo Presidente da República (Art. 35, I e II, Lei 13.140/15). Esse tipo de transação terá seus requisitos e condições definidos em resolução administrativa própria (Art. $35, \S 1^{\circ}$, Lei 13.140/15).

Ressalta-se, ainda, que essa aplicação da mediação na Administração Pública ganhou um grau de importância tão elevado, que a instauração do processo consensual administrativo possui o condão de suspender o prazo prescricional para ajuizamento de demanda judicial. Além disso, o acordo entre as partes se torna um título executivo extrajudicial, sendo possível a realização do seu processo de execução no âmbito judicial.

Dessa forma, não se tem mais dúvidas da possibilidade de aplicação dos meios autocompositivos no âmbito da administração pública, sendo, inclusive, algo que deveria ser incentivado, como forma de alcançar o próprio interesse público, bem como concretizar princípios básicos da Administração Pública, tais como a eficiência.

\section{A UTILIZAÇÃO DA AUTOCOMPOSIÇÃO COMO FORMA DE CONCRETIZAÇÃO DO PRINCÍPIO DA EFICIÊNCIA ADMINISTRATIVA}

O princípio da eficiência é um dos pilares que moldam a atuação da Administração Pública em suas relações. Conforme o Art. 37 da CF, "a administração pública direta e indireta de qualquer dos Poderes da União, dos Estados, do Distrito Federal e dos Municípios, obedecerá aos princípios da legalidade, impessoalidade, moralidade, publicidade e eficiência".

Apesar da atual disposição expressa no texto constitucional, tal princípio não é algo recente. Antes mesmo da Emenda Constitucional n 19 - responsável por adicionar a eficiência ao rol de princípios constitucionais a serem obedecidos pela Administração Pública - se falava, seja no âmbito doutrinário, legislativo ou jurisprudencial, desse princípio. O dever de boa Administração, respaldado pela Lei n.200/1967, é um exemplo de tal incidência (FLESCH, 2015, p. 212). Além disso, a própria Constituição, de maneira implícita, tratava da eficiência como padrão de comportamento dos órgãos públicos (MODESTO, 2000, p. 108). A doutrina jurídica também não se esquivou de analisar a temática. Segundo Paulo Modesto (2000, p. 109), autores como Herly Lopes Meirelles já apontavam que, entre os poderes e deveres do administrador público, estaria o chamado dever de eficiência, podendo este ser comparado ao dever de boa administração da doutrina italiana.

Todavia, é com a Emenda Constitucional Na 19 que a eficiência assume destaque na atuação da Administração Pública. A partir disso, passou-se a se analisar o seu conteúdo com maior profundidade, suas formas de aplicação, bem como os seus efeitos no modo de agir da máquina pública.

Nesse sentido, no âmbito do Direito Público, pode-se definir eficiência como a maximização dos recursos disponíveis para alcançar determinado fim, sendo este alcançado de maneira satisfatória e excelente (MODESTO, 2000, p. 113). Segundo Maria Sylvia Zanella Di Pietro e Wallace Paiva Martins Junior (2014, p. 485): 
Dessa forma, podemos compreender a eficiência através da relação de dois aspectos: meios disponíveis e fins alcançados. A atuação eficiente diz respeito à utilização adequada dos meios disponíveis para alcançar um fim, sendo este, no final, alcançado de forma excelente. São três os critérios para se averiguar a utilização do meio adequado para alcance de um fim: a idoneidade, a economicidade e a satisfação (MODESTO, 2000, p. 113).

Portanto, para uma correta aplicação do princípio da eficiência administrativa, o agente público deve optar pela ação mais eficaz, mais otimizada e com maior qualidade (dentre as disponíveis), para que o fim seja alcançado de uma forma excelente.

Por conta desse conteúdo, resta impossível estipular todas as concretizações de tal princípio na prática, uma vez que são inúmeras, sendo evidente mais uma das suas características: a pluridimensionalidade. A eficiência pode se manifestar de diversas formas, isto é, em diversas ações da Administração Pública, como por exemplo, na atuação em litígios.

É nesse aspecto que se concentra a atuação dos métodos consensuais, sendo meios adequados para se atingir uma solução eficiente em determinado litígio. Afinal, é óbvio que o prolongamento de um processo gera custos e tempo para a Administração Pública. Seja em razão das despesas consideráveis com a remuneração de seus procuradores, que poderiam se concentrar em outros processos, cujo o prolongamento realmente se faz necessário. Seja em virtude dos próprios gastos no fim do litígio, por meio do valor das condenações, dos honorários e dos juros moratórios, que poderiam ter sido evitados com a ocorrência de um acordo entre a Administração Pública e a outra parte envolvida.

Desse modo, a correta utilização dos métodos consensuais de resolução de conflitos serviria como forma de concretização do princípio da eficiência. O Administrador Público, ao analisar determinado caso, optaria pela consensualidade (se for o meio mais adequado) para a sua resolução. Compatibilizando, assim, a ideia de eficiência (ação idônea, econômica e satisfatória para alcance excelente de determinado fim), com o já citado sistema multiportas de Justiça, que determina que para cada caso há uma solução adequada dentre as disponíveis.

O problema, no caso da Administração Pública, é o estabelecimento de critérios para a escolha entre a consensualidade e a Jurisdição como via mais adequada para solução de determinado conflito. Um excelente critério para a realização desse filtro é a chamada análise de risco (FAGUNDEZ; GOULART, 2016, p. 154). De acordo com tal critério, na busca pela concretização da eficiência no âmbito dos litígios, o administrador deve averiguar o grau de certeza do direito da outra parte, bem como a probabilidade de vitória por parte do órgão público. Se o autor da demanda assistir razão, a atitude mais eficiente seria o reconhecimento total ou parcial do pedido. Já na hipótese de ausência de fundamento fático ou jurídico ao autor da demanda, a ação mais prudente seria o prosseguimento do processo. Finalmente, nos casos em que há dúvida sobre a procedência ou não do pedido do autor, ocorrerá espaço para a aplicação dos métodos consensuais, sendo esta, a depender do caso, a solução 
mais eficiente (FAGUNDEZ; GOULART, 2016, p. 154).

Por fim, retomando a discussão travada anteriormente, relacionada à aplicação dos meios consensuais em litígios envolvendo o interesse público primário e secundário, há de se fazer uma ponderação. Agora, sob a ótica do princípio da eficiência, bem como do dever de autotutela da Administração Pública, não se pode afirmar no sentido de ser impossível a aplicação de meios consensuais em litígios envolvendo o interesse público primário da Administração.

O referido interesse público, associado primordialmente ao interesse público primário, se mostra, a princípio, antagônico à possibilidade de transação. [...] Contudo, essa estreita visão pode levar a considerações errôneas. Não se pode presumir que a Administração Pública está proibida de abdicar de pleito próprio ou de reconhecer pretensões individuais, revendo os seu próprios atos ilegais, independentemente de intervenção judicial. Trata-se de postura decorrente do seu poder administrativo de autotutela e do dever de cumprir o direito (princípio da juridicidade) e, com isso, atender ao interesse público (PERLINGUEIRO, 2017, p. 138).

A Administração Pública, visando corrigir os erros cometidos, bem como alcançar a solução mais eficiente para o caso concreto, poderá reconhecer o dano causado, utilizando-se, para tanto, do dever administrativo de autotutela e/ou dos meios consensuais.

Aliás, vale registrar que a disposição sobre direitos e interesses transitoriamente defendidos pela administração em contrariedade ao direito pátrio, bem como a utilização de meios consensuais de resolução de conflitos representa, inclusive, ao lado das atividades consultiva e contenciosa, uma das funções típicas da advocacia pública, qual seja, a de controle interno de juridicidade dos atos da Administração Pública (MADUREIRA, 2015, p. 102). ${ }^{1}$

Com efeito, o controle interno da juridicidade é realizado, concretamente, por ocasião do exercício das atividades contenciosa e consultiva pelos advogados públicos (MADUREIRA, 2015, p.106), sendo a representação judicial, a consultoria e o assessoramento reforçados com a função de controle interno de juridicidade, "que irrompe como consequência natural das três primeiras, por ser desempenhada no exercício daquelas" (GRANDE JUNIOR, 2009, p. 64).

Dessa forma, quando do exercício da consultoria jurídica, o advogado público naturalmente controla a aplicação do direito pela Administração Pública, conduzindo-a à postura administrativa mais adequada ao caso concreto, dentro das exigências do interesse público, ou seja, dentro da observância na ordem jurídica (correta aplicação do direito). No mesmo contexto, no controle de juridicidade do agir administrativo realizado no âmbito da atividade de contencioso judicial, é possível que o advogado público disponha de interesses transitoriamente defendidos em juízo, em uma lide concreta, que se revelem contrários ao Direito, cumprindo-lhe "empregar os mecanismos que o direito põe à sua disposição para reverter essa situação", que se revela ilegal (ou antijurídica), "deixando de apresentar defesa e recursos, bem como procurando promover a conciliação no processo" (MADUREIRA, 2015, p. 312). 
Assim, em tais hipóteses, valendo-se dos critérios já citados, a Administração Pública poderá utilizar os meios consensuais nos litígios envolvendo o interesse público primário, o que representa a aplicação correta do direito pátrio por meio do controle interno de juridicidade do agir administrativo, sendo, inclusive, um instrumento útil para alcance desse mesmo fim, uma vez que a aplicação correta do princípio da eficiência é uma das vias a serem percorridas para a realização do interesse público.

\section{CONCLUSÃO}

A tamanha importância atribuída, no nosso atual ordenamento jurídico, aos métodos adequados de resoluções de conflitos, especialmente com as inovações trazidas pela Resolução 125/2010 do CNJ, pelo CPC/2015 e pela Lei 13.140/15, também refletiram na resolução de conflitos pela Administração Pública.

Conforme se pôde observar, a Administração Pública, como pessoa jurídica que mais participa de litígios no Brasil, também está inserida no modelo atual de Justiça Multiportas, onde se faculta às partes a escolha do método de resolução mais adequado para o seu litígio. Entretanto, em virtude das suas particularidades, a utilização de tais meios deve obedecer alguns critérios, seja quando o direito em questão for disponível, seja quando for indisponível. No caso do último, a aplicação é mais rigorosa, devendo se observar se a utilização da consensualidade será uma via adequada para o alcance do próprio interesse público primário, na forma de concretização do dever de autotutela e do princípio da eficiência administrativa.

Assim, em tais casos, a utilização dos meios consensuais (mediação e conciliação) será uma importante arma para a atuação de uma Administração Pública cada vez mais eficiente, célere, econômica e preocupada com a realização do interesse público, que, em última análise, é a sua razão de existência.

\section{NOTAS}

1. Temática abordada na Dissertação de Mestrado apresentada por Felipe Barbosa de Menezes. MENEZES, F. B. A remessa necessária no código de processo civil de 2015 e seus desdobramentos na atuação da Advocacia Pública: problema ou solução? Vitória, 2016. Dissertação (Mestrado em Direito Processual Civil) - Universidade Federal do Espírito Santo.

\section{REFERÊNCIAS}

ALVARO DE OLIVEIRA, Carlos Alberto. Garantia do contraditório. Revista da Faculdade de Direito da Universidade Federal do Rio Grande do Sul, Porto Alegre, v. 15, 1998. Disponível em: http://www.ufrgs. br/ppgd/doutrina/oliveir1.htm. Acesso em 03 Jun. 2018.

CAMBI, Eduardo Augusto Salomão; MACHADO DE SOUZA, F.. A disponibilidade do interesse público no Novo Código de Processo Civil e o princípio da eficiência da Administração. Revista da AJURIS Associação dos Juízes do Rio Grande do Sul, v. 44, p. 107-154, 2017.

CAPPELLETTI, Mauro. Acesso à Justiça. Tradução de Ellen Gracie Northfleet. Porto Alegre, Fabris, 
1988. $168 \mathrm{p}$.

CNJ. Relatório Justiça em Números 2015. Disponível em: http://www.cnj.jus.br/programas-e-acoes/pjjustica-em-numeros. Acesso em: 02 jun. 2018.

CUNHA, Leonardo Carneiro da. A Fazenda Pública em juízo. 15ª. ed. Rio de Janeiro: Forense, 2018. $941 \mathrm{p}$.

DIDIER JR., Fredie. Curso de Direito Processual Civil, vol. 1. 18 ed. Salvador: Juspodivim, 2007. 799 p.

DI PIETRO, Maria Sylvia Zanella; MARTINS JUNIOR, Wallace Paiva. Teoria geral e princípios do direito administrativo. 1. ed. São Paulo: Thomson Reuters. Ed. Revista dos Tribunais, 2014. v. 2. 635 p.

EIDT, Elisa Berton. Os institutos da mediação e da conciliação e a possibilidade de sua aplicação no âmbito da administração pública. RPGE. Porto Alegre, v. 36, nº 75, p.55-74, 2015.

FAGUNDEZ, P. R. Á.; GOULART, J. R. O marco legal da mediação no Brasil: aplicabilidade na Administração Pública. Revista de Formas Consensuais de Solução de Conflito. v. 2, n. 2, p. 148 164, 2016.

FLESCH, Carla Machado. A submissão da Administração Pública ao princípio da eficiência visando à satisfatória consecução de seus fins. Boletim Científico ESMPU, a. 14, N. 45, p. 211 - 237, 2015.

GRANDE JÚNIOR, Cláudio. Advocacia pública: estudo classificatório de direito comparado. In: Jefferson Carús Guedes; Luciane Moessa de Souza. (Org.). Advocacia de Estado: questões institucionais para a construção de um estado de Justiça. Estudos em homenagem a Diogo de Figueiredo Moreira Neto e José Antionio Dias Toffoli. 1ed. Belo Horizonte: Fórum, 2009. v. 1. p. 59-86.

MACHADO DE SOUZA, F. A disponibilidade do interesse público no Novo Código de Processo Civil e o princípio da eficiência da Administração. Revista da AJURIS - Associação dos Juízes do Rio Grande do Sul, v. 44, p. 129-153, 2017.

MADUREIRA, C. P. . Advocacia Pública. 1. ed. Belo Horizonte: Fórum, 2015. v. 1. 388p.

MELLO, Celso Antônio Bandeira de. Curso de Direito Administrativo. 21. Ed. Ver. São Paulo: Malheiros, 2006. $1063 \mathrm{p}$.

MENEZES, F. B. A remessa necessária no código de processo civil de 2015 e seus desdobramentos na atuação da Advocacia Pública: problema ou solução?. 2016. Dissertação (Mestrado) - Curso de Direito Processual Civil, Universidade Federal do Espírito Santo, Vitória, 2016.

MIRANDA, Pontes de. Tratado de Direito Privado. 1997, p.170.

MODESTO, Paulo. Notas para um debate sobre o princípio da eficiência. Revista do Serviço Público, v. 51, p. 105-116, 2000.

PERLINGUEIRO, Gabriel. As possibilidades de solução consensual de conflitos judiciais com a Administração Pública. Revista Eletrônica de Direito Processual - REDP, v. 18, p. 122-145, 2017. 
PINHO, Humberto Dalla Bernardina de. O novo CPC e a mediação: reflexões e ponderações. Revista de Informação Legislativa, Brasília, DF: Senado Federal. v. 48, n. 190, t.1, p. 219-235, 2011.

SICA, Heitor Vitor Mendonça. Arbitragem e Fazenda Pública. [S.1], 2015. Disponível em: $\underline{\text { http://bit. }}$ ly/2fLZNOe. Acesso em: 07 jun. 2018.

Recebido em: 21/11/2018

Aceito em: 04/12/2018 